\title{
Land-sparing vs Land-sharing with incomplete policies
}

\author{
Guy MEUNIER \\ INRA-UR1303 ALISS \& Ecole Polytechnique \\ guy.meunier@ivry.inra.fr \\ Preliminary version
}

\begin{abstract}
This article analyzes the trade-off between yield and farmed area when a valuable species is affected by agricultural practices. It revisits, from an economic perspective, the "land-sparing versus land-sharing" debate elaborated in conservation biology. It uses the methodology of the density-yield curve: The density of the species over farmland is a decreasing function of the yield. It is shown that the optimal yield is either increasing or decreasing with respect to the value of the species depending on the shape of the density-yield curve. Land sparing and land-sharing are not necessarily antagonistic: for sufficiently elastic demand function, both the optimal yield and the farmed area decreases with the value of the species. A general assessment of a second best policy is performed and several particular policies are considered: a subsidy on biodiversity in farms, a tax or subsidy on farmland, a tax or subsidy on a dirty input. In several cases, the first-best strategy and the second-best one induce contrasting effects on the yield.
\end{abstract}

JEL Classification: H23; Q15; Q57

Keywords: Biodiversity; Agriculture; Second-best policy. 


\section{Introduction}

The increase of world population rises concerns about the capacity of the food production sector to feed 9 billions people at an acceptable environmental cost. The development of a wildlife friendly agriculture in the farm may come at cost: the associated reduction of yield can induce an increase of the total area needed for agriculture. The optimal strategy is global and must consider the total environmental cost over both farmed and unfarmed land. Opposite to a strategy of "land-sharing", with wildlife friendly agriculture over a wide area of land, there is a strategy of "land-sparing" consisting in intensive farming over a small area of land.

Green et al. (2005) have analyzed the trade-off between yield and farmed area from a biological point of view. They showed that the optimal strategy for the species conservation between land-sparing and land-sharing depends on the shape of the density-yield curve (e.g. Figure 1). The objective of the present article is to analyze this trade-off, between yield and farmed area, in an economic framework, and to determine how the optimal strategy depends upon institutional factors. If a policy option is optimal in a first-best setting it might not be so in a second-best one.

The model used is a partial equilibrium model of the market for an agricultural good produced over the habitat of a valuable species. The total size of the habitat is split between farmed and unfarmed land. The density of the species over an hectare is a function of the yield. The optimal, welfare maximizing, yield and production are described. The optimal yield is between the laissez-faire yield and the conservation optimal yield; it is either higher or lower than the laissez-faire yield, and it is either increasing or decreasing with respect to the value of the species, approaching the conservation optimum.

The introduction of the demand for food allows to consider its adjustment. There is, indeed, a cost associated to the conservation of the species and food consumption decreases when the value of the species is internalized. Therefore, the demand price-elasticity determines whether the total farmed area actually increases when the yield decreases. If demand for food is elastic both lower yield and larger unfarmed area are optimal when the density-yield curve is concave. A scenario consistent with the European situation.

Some second-best policies are analyzed in order to clarify the advantages and drawbacks of real-world policies. Indeed, real-world policies are of the second-best type given the difficulty to implement a subsidy on specimen per hectare. A general assessment of a second-best policy is first performed. 
Whether a policy is welfare enhancing will depends on the shape of the density-yield curve and the elasticity of the demand function. For instance, even if land-sharing is the optimal first-best strategy, it can be welfare enhancing to implement natural reserves if the demand is elastic. In such a case, the quantity of food consumed should decrease sufficiently to ensure that the biodiversity on unfarmed land compensates for the loss on farmed land. The analysis of second best policy highlights the fact that whether a particular agricultural practice should be promoted depends on the policy used.

The rest of the article is organized as follow. The related literature is reviewed in the next section (Section 2). The model is introduced (Section 3). The optimal (first-best) policy is described in Section 4, and second-best policies in section 5 . The main limitations of the model are discussed in Section 6. Section 7 concludes.

\section{$1.1 \quad$ Literature review}

The motivation for the present work originates from the work of Green et al. (2005). They analyze the biological consequences of different mode of farming at a global scale. They maximize a species population subject to a food production constraint. They show that if the density yield curve is concave land-sharing is the optimal strategy, a relatively large population can be maintained in low-yield farms covering all the area. However, if the population is more sensitive to the initial increases in yield (for instance because of deforestation) it is optimal to spare land for nature and implement intensive farming on the smallest possible area.

Phalan et al. (2011) construct density-yield curves for bird and tree species in southwest Ghana and northern India. Figure 1 illustrate their results. They conclude that land-sparing is the optimal strategy. However, land-sparing has been criticized for the possible difficulty to implement it. Once, some land has been irreversibly converted to intensive farming, it might be difficult to enforce the actual sparing of the rest of the land (Godfray, 2011, Ewers et al. 2009). The present analysis of second best policy partly answers this concern, even though irreversibility is not introduced. The analysis show under which condition a dirty input should be subsidized or taxed. That the optimal yield is higher than the laissez-faire yield does not imply that intensive farming should be subsidized. If land-sparing cannot be effectively enforced, to subsidize intensive farming induces an over-expansion of farm- 


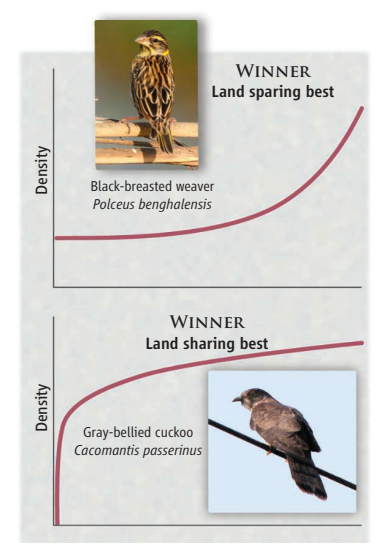

(a) Some winners from increasing yield

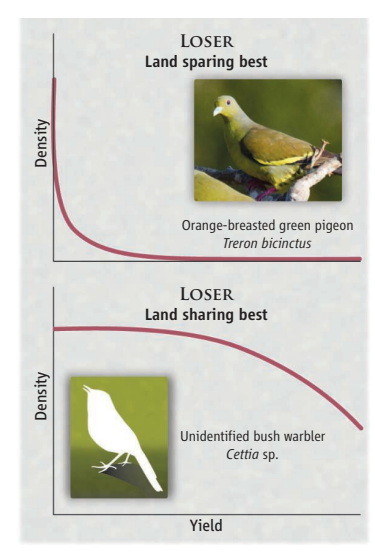

(b) Some losers

Figure 1: Density-yield curves for four species of birds in northern India (Phalan et al.; 2011). The curves are then used to determine the optimal strategy between land-sparing and land-sharing for conservation. (source: Godfray (2011))

ing (compared to the first-best policy) which can compensate for the benefits from an increased yield. This negative result arises if the demand for food is sufficiently price-elastic. If the demand for food is inelastic, as it might be in a developing a country, then subsidizing farming enhances welfare.

The relationship between agricultural practices and some species densities have been investigated (Fuller et al., 2005, Chamberlain et al.; 2010; Firbank et al.; 2008). In particular, the comparison of organic and conventional agriculture has received an important attention. Many studies conclude that organic farming enhances biodiversity in the farm, even though some species might be adversely affected (see the meta-analysis by Bengtsson et al.; 2005). Most studies also conclude that the yield of organic farming is lower than the yield of conventional farming, but results are highly variable (de Ponti et al.; 2012, Seufert et al.; 2012).

Some authors have studied whether an increase of the yield (as an exogenous shock) actually spare land for nature (e.g. Rudel et al.; 2009; Ewers et al.; 2009). The causes of deforestation has also been analyzed both theoretically and empirically (see Angelsen and Kaimowitz; 1999, for a review). Whether an increase of agricultural productivity leads to a decrease of farmed 
area depends upon the price-elasticity of demand, which also plays a key role in the analysis of second-best policy in the present work. Whether, historically, increased yields have been associated with reduced farmed area might be a good environmental news that should not prevent the implementation of conservation policy. Indeed, the optimal policy should be concerned both by agricultural practices and farmed area and not focused on the former.

In the economic literature, in addition to the literature on deforestation already mentioned, several theoretical articles consider the relationship between land-use and biodiversity. A recent literature developed from the general biological equilibrium developed by Tschirhart (2000). In particular, Eichner and Pethig (2006) links a general equilibrium of the economy to a general equilibrium of an ecosystem. In their model a land is either used for human activity or for wildlife, there is no intermediate levels (see also Christiaans et al. 2007; Pethig, 2004, on pesticide uses). They do not analyze the trade-off between the area used and the density of human activity. However, a natural extension of the present work would be to develop the biological side of the model in the spirit of these works.

Another strand of the literature is concerned by the influence of the spatial distribution of agricultural activity on biodiversity. Several authors have analyzed the incentive for farmers to reduce habitat fragmentation and the effectiveness of various policies (Lewis and Plantinga; 2007; Lewis et al. 2009; Parkhurst et al. 2002, Parkhurst and Shogren; 2007; Bamière et al. 2013). In these articles too the land is either farmed or not and the trade-off highlighted in the present article is not considered.

The two recent working papers by Martinet and Barraquand (2012) and Couvet et al. (2013) are closer to the present work. They both consider the land-sparing versus land-sharing debate and consider three potential land uses: wildlife friendly farming (or organic), intensive farming and natural reserve. While Martinet and Barraquand (2012) analyze the influence of a subsidy on natural reserve and a tax on fertilizer on the allocation of land, Couvet et al. (2013) consider the effects of a shift from intensive to extensive farming. Couvet et al. (2013) highlight that, with a sufficiently elastic demand for food, the higher cost of extensive farming can imply that the total land farmed is reduced despite the reduced yield. These two articles do not analyze optimal and second-best policies.

Finally, the analysis of second-best policy performed here could be related to the literature on the indirect regulation of non point source pollution. When individual pollution cannot be easily measured Griffin and Bromley 
(1982) shows that a system of tax on inputs can replicate the first-best scheme (Shortle et al.; 1998, see also). Here, situations in which only one of two polluting inputs (land or agricultural intensity) can be taxed are considered. Substitution with the second input explain that the second-best policy can consist in an opposite effect on the regulated pollutant than the first-best one.

\section{Model}

We consider the market for one food product, the total quantity produced is $F$ (in t.). It creates the gross consumer surplus $S(F)$ (in $\$$ ), a positive increasing and concave function. The corresponding price function $P(F)$, equal to $S^{\prime}$, is positive and decreasing. The price-elasticity of the demand for food is denoted $\epsilon$,

$$
\epsilon(F)=\frac{P}{P^{\prime}(F) F}
$$

On the supply side, the yield is denoted $y$ (in t/ha) and the quantity of land farmed $L$ (in ha) so that $F=y L$. The cost of farming is $c(y)(\$ /$ ha), it is the cost to produce $y$ tons of food on a hectare of land. The total cost to produce $F$ is then $c(y) F / y$. The cost $c(y)$ is positive, increasing and convex. It is assumed that there is a fixed cost associated to land conversion, that is $c(0)>0$, so that average costs are first decreasing and then increasing. The cost-minimizing yield is denoted $y_{0}$ it is the solution of

$$
c^{\prime}(y)=c(y) / y
$$

The marginal and the average cost are equalized at $y_{0}$, which is the minimum efficient scale.

The market is assumed perfectly competitive. If no regulation is implemented the total profit from land-use is

$$
\pi=p y L-c(y) L=p F-\frac{c(y)}{y} F
$$

If land is abundant (the constraint on land is not binding), farmers choose the yield $y_{0}$ per hectare farmed and the quantity of land farmed $L_{0}$ is such that the price of food is equal to the cost $c\left(y_{0}\right) / y_{0}$. The yield $y_{0}$ will be 
called the laissez-faire yield to stress that it is the yield chosen without any regulation 1

There is one valuable species and the size of its population over a particular piece of land is a function of the yield ${ }^{2}$ The total size of the habitat is $\bar{L}$. The density on a hectare of farmland is $b(y)$ (specimen/ha), a positive and decreasing function of the yield ${ }^{3}$ The total population on the habitat under consideration is the sum of the population on unfarmed land $b(0)(\bar{L}-L)$ and on farmed land $b(y) L$. The marginal value of biodiversity is $\beta(\$ /$ specimen).

Total welfare is then

$$
W=S(y L)-c(y) L+\beta[b(0)(\bar{L}-L)+b(y) L]
$$

which could be written as a function of yield and food production:

$$
W(y, F)=S(F)-\left[\frac{c(y)}{y}+\beta \frac{b(0)-b(y)}{y}\right] F+\beta b(0) \bar{L} .
$$

To ensure that there is a unique interior optimum, the value of the species is assumed sufficiently small so that $c^{\prime \prime}(y)>\beta b^{\prime \prime}(y)$ for all $y$. This condition is always satisfied if the density-yield curve is concave and the species valuable. If the density yield curve is convex and $\beta$ is large it does not hold, in that case Welfare is not concave with respect to the yield and there can be several local optima. We rule out this possibility.

Figure 1(b) provides examples of a convex and a concave density-yield curve (source Godfray; 2011). Indeed, more complex curves (e.g. first convex then concave) are possible and would be more realistic. There is a maximum yield $\bar{y}$ at which $b$ is null and production cost is sufficiently large at this yield that it is never optimal to adopt it.

\footnotetext{
${ }^{1}$ It is possible to consider an equivalent decentralized process, in which each owner of a piece of land decide whether to farm or not (entry stage) and then chooses its production $y$ (production stage). With this decentralized process, $y$ is such that $p=c^{\prime}(y)$ (price equals marginal cost) and the entry process ensures that profits are null: $p y=c(y)$.

${ }^{2}$ We do not consider the issues of habitat fragmentation and the spatial distribution of farming activities.

3 Phalan et al. (2011) establish empirically these relationships for several bird species. They found that some species might benefit from an increased yield, a possibility not considered here.
} 


\section{The optimal policy}

The optimal policy consists in a couple of yield and quantity of food $\left(y^{*}(\beta)\right.$, $\left.F^{*}(\beta)\right)$ that maximizes welfare subject to the constraint $L \leq \bar{L}$. If the constraint is not binding the optimal policy is characterized by the two first order conditions:4

$$
\begin{aligned}
P(F) & =\frac{c(y)}{y}+\beta \frac{b(0)-b(y)}{y} \\
c(y)-c^{\prime}(y) y & =\beta\left[-b^{\prime}(y) y-(b(0)-b(y))\right] .
\end{aligned}
$$

The first equation states that the price of food should be equalized with its marginal cost, which includes the environmental cost of agriculture. The second equation represents the arbitrage made when choosing the optimal yield between the economic benefits and the environmental damages. The left-hand-side of equation (6) is the gain due to the influence of the yield on the cost, it is decreasing and null at the minimum efficient scale $y_{0}$. The right hand side is the environmental cost from an increase of the yield. This environmental cost is the difference between the direct costs associated with the increase of the yield and the indirect gain obtained from the reduction of the farmland area $(b(0)-b(y)$ per ha). Since both sides of the equation (6) can be positive or negative, the arbitrage is not easy to appreciate.

Proposition 1 The quantity of food produced decreases with respect to the value of the species $\beta$.

If land is abundant, i.e. $F^{*}<y^{*} \bar{L}$, the optimal yield decreases (resp. increases) with respect to $\beta$ if $b(y)$ is concave (resp. convex).

If land is scarce, i.e. $F^{*}=y^{*} \bar{L}$, the optimal yield is decreasing with respect to $\beta$.

Proof.

1. The optimal quantity of food satisfies:

$$
P\left(F^{*}\right)=\frac{c\left(y^{*}\right)}{y^{*}}+\beta \frac{b(0)-b\left(y^{*}\right)}{y^{*}}
$$

\footnotetext{
${ }^{4}$ The assumption on $\beta: c^{\prime \prime}<\beta b^{\prime \prime}$ ensures that welfare is quasi-concave: Let us show that if $y$ and $F$ satisfies the couple of conditions 5 and 6 then the second order conditions are satisfied. It is so because i) $\partial W / \partial y$ is linear in $\mathrm{F}$, so $\partial W^{2} / \partial y \partial F=[\partial W / \partial y] / F$ is null if $y$ satisfies the equation (6), and ii) the second order derivative w.r.t. to the yield is $\partial W^{2} / \partial y^{2}=F / y^{2}\left(c^{\prime \prime}-\beta b^{\prime \prime}\right)-2 F / y \partial W / \partial y=F / y^{2}\left(c^{\prime \prime}-\beta b^{\prime \prime}\right)<0$ if $y$ satisfies 6 .
} 
the derivative of the right hand side with respect to $\beta$ is, by the envelop theorem, $\left[b(0)-b\left(y^{*}\right)\right] / y^{*}$ which is positive. The price function being a decreasing function, the optimal quantity of food is decreasing w.r.t. $\beta$.

2. The derivative of the right hand side of equation (6) is $-b^{\prime \prime}(y)$ and the right hand side is null at $y=0$.

- If $b($.$) is concave:$

The marginal environmental damage is increasing $\left(-b^{\prime \prime}>0\right)$, since it is null at $y=0$, it is positive. At the optimum, a marginal change of $\beta$ would increase the marginal environmental damage and subsequently decrease the optimal yield. (at the interior optimum the second order condition is satisfied and the effect of a change of $\beta$ on the optimal yield is the opposite of its effect on the right hand side of 60.

- If $b($.$) is convex:$

The right hand side of 6 is decreasing and null at zero, therefore it is negative. The optimal yield is increasing with respect to $\beta$.

The Proposition is illustrated by Figure 2, With a concave density yield curve (Figure 2(a)), the situation looks familiar: there is an increasing environmental damage associated to an increase of the yield and the optimal yield should be lower than the laissez-faire yield. The case of onvex density-yield curve is different, as illustrated Figure 2(b). With a convex density-yield curve, the species is very sensitive to the first increase of the yield. The marginal environmental damage is decreasing with respect to the yield, and the environmental cost is actually a gain thanks to the sparing of land. It is optimal to spare land in which the species is abundant and increase yield on farmland 5

\footnotetext{
${ }^{5}$ If the density-yield curve is convex, the environmental damage is concave, and the right hand side of 6 is decreasing with respect to the yield. The environmental cost is actually a gain which is increasing with respect to the yield and multiple local optima may exist for sufficiently large value of $\beta$. All these interior optima are on the right of the minimum efficient scale. When the value of the species $\beta$ increases one may jump from one interior equilibrium to another, Proposition 1 is still true because the new equilibrium is situated to the right of the old one.
} 

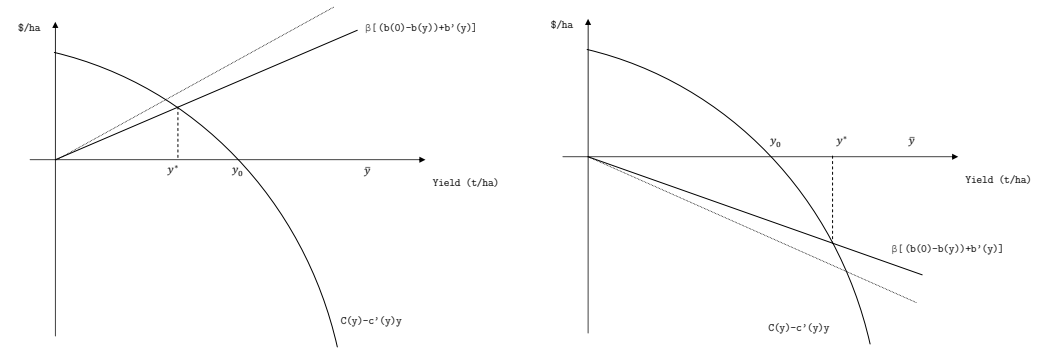

(a) With a concave density-yield (b) With a convex density-yield curve, the optimal yield is lower curve, the optimal yield is higher than the efficient minimum scale than the efficient minimum scale

Figure 2: The determination of the optimal yield with a concave (resp. convex) density yield curve. The dotted line represents the effect of an increase of the value of the species.

In Figure 2 it is assumed that land is abundant so that any change of the yield for a given food production is associated with an adjustment of the farmed area. If land is scarce and already fully exploited, a marginal increase of the yield does not trigger a reduction of the area farmed. In such a case a marginal increase of the value of the species $\beta$ induces a reduction of the yield whatever the shape of the density-yield curve.

Proposition 1 illustrates that the optimal farming technique depends on what is being held fixed. If one considers a fixed amount land, it is always optimal to reduce the yield and adopt wildlife-friendly technique. However, if the adjustment of the farmed area is considered, the optimal yield is either increasing or decreasing with respect to the value of the species, depending on the shape of the density-yield curve. For the rest of the article the amount of land will be considered abundant so that in all cases considered $\bar{L}$ is sufficiently large to ensure that the constraint is never binding.

In their article, Green et al. (2005) compute the optimal strategy from a conservationist perspective subject to a constraint on the quantity of food produced and the quantity of land available. Absent any cost consideration, it could be seen from Figure 2 that the optimal strategy is in a corner: it is optimal to set the lowest (resp. highest) possible yield with a concave (resp. convex) density-yield curve. Furthermore, their implicit demand for food is totally inelastic $(\epsilon=0)$; with an elastic demand for food, the quantity of food produced is reduced by the internalization of biodiversity and the total 
farmed area depends upon demand elasticity.

Proposition 2 If the density-yield curve is convex, the optimal farmed area is decreasing with respect to the value of the species.

If the density-yield curve is concave, the optimal farmed area is decreasing (resp. increasing) with respect to the value of the species if the elasticity of the demand function is lower (resp. higher) than:

$$
\frac{c\left(y^{*}\right)+\beta\left(b(0)-b\left(y^{*}\right)\right)}{\beta\left(b(0)-b\left(y^{*}\right)\right)} \times \frac{\beta\left(b^{\prime} y^{*}+b(0)-b\left(y^{*}\right)\right)}{\left(c^{\prime \prime}-\beta b^{\prime \prime}\right) y^{* 2}}(<0)
$$

Proof. The optimal farmed area is $L^{*}(\beta)=F^{*}(\beta) / y^{*}(\beta)$.

If the density yield curve is convex, $L^{*}$ is decreasing w.r.t. $\beta$ because $F^{*}$ is decreasing and $y^{*}$ is increasing w.r.t. $\beta$.

If the density yield curve is concave, let us write the $\beta$-elasticity of the farmed area

$$
\frac{\beta L^{* \prime}}{L^{*}}=\frac{\beta F^{* \prime}}{F^{*}}-\frac{\beta y^{* \prime}}{y^{*}}
$$

and using equation (5) and (6) gives

$$
\frac{\beta F^{* \prime}}{F^{*}}=\frac{\beta(b(0)-b(y))}{c(y)+\beta(b(0)-b(y))} \frac{1}{\epsilon} \text { and } \frac{\beta y^{* \prime}}{y^{*}}=\frac{\beta}{y^{*}} \frac{b^{\prime} y^{*}+\left(b(0)-b\left(y^{*}\right)\right.}{\left(c^{\prime \prime}-\beta b^{\prime \prime}\right) y^{* 2}}
$$

injecting these two equations into the expression $(8)$ gives the result.

Even if the optimal yield decreases with respect to the value of biodiversity, the optimal quantity of farmland can decrease if demand is sufficiently price elastic. The threshold price elasticity (7) is the product of two factors: The first is positive, it is the inverse of the $\beta$-elasticity of the total production cost or, equivalently, the relative weight of the environmental component in the farming cost. The second factor is the $\beta$-elasticity of the optimal yield (negative). An increase of the value of the species decreases the yield and increases the cost. The total farmed area decreases despite the reduction of the yield if the increase of the cost is sufficiently large (a small first factor in 7) to trigger a large reduction of the quantity consumed.

Green et al. (2005) argue that a concave density yield curve is more likely in Europe in which farming has been extensively used for a long a time. By contrast land-sparing is optimal in developing countries with large area of old-growth forests. Demand for food is also more elastic (i.e. lower $\epsilon$ ) in Europe than in developing countries. Therefore, it seems well possible that 
both wildlife-friendly practices and the implementation of natural reserves is the optimal strategy in Europe. A result that might reconcile the apparent opposition between wildlife friendly practices and the protection of natural land.

The result only concerns a small change of $\beta$. Larger changes might generate non monotonic patterns. The threshold elasticity depends upon $\beta$ both directly and indirectly via the yield. It is possible that the sensitivity of the yield associated to $\beta$, the second factor in $(7)$, progressively increase toward zero, while the share in the cost of the environmental component increases toward unityas $\beta$ increases. The two evolutions imply that the threshold elasticity is increasing toward zero, and that the farmed area has a bell-shaped evolution w.r.t. to the value of the species. For initial increments, there is a strong reduction of the yield and a relatively small increase of the production cost so that the demand for food is not strongly affected and farmed area increases. For larger value of the species, the yield is less reduced and most environmental protection occurs via a reduction of the consumption of food and the associated farmed area.

\section{Second-best policy.}

The optimal allocation has been described by a yield, a farming technique, and the farmed area. This allocation can be implemented by setting directly these two quantities via technical standards and natural reserves. Indeed, it can also been implemented by a Pigouvian subsidy on each species specimen equals to $\beta$.

In this section several situations are considered in which the regulator cannot implement the optimal policy. Several reasons could be advanced to explain that it is not feasible to implement the subsidy on the species specimen or directly set the optimal yield and optimal farmed area. In addition to the difficulty to estimate the density of a species, if property rights are not well defined over unfarmed land it is not possible to remunerate an owner to create the incentive for land conservation.

\subsection{A general assessment}

The regulation is represented by a variable $r$. The regulation influences the incentive to farm and the choice of the yield, it does not have other 
effects. For instance, public funds are costless and if the regulation is a tax or a subsidy the associated monetary transfers are welfare neutral. With a regulation $r$ the perceived marginal cost of food production is $C(y, r)$. The profit of the representative land-owner is:

$$
\pi(y, F, P)=P F-C(y, r) F
$$

The equilibrium yield minimizes the production cost and the quantity of food produced is such that the price is equal to the marginal cost $C(y, r)$. Let us denote $y^{R}(r)$ and $F^{R}(r)$ the two equilibrium quantities. They satisfy:

$$
P\left(F^{R}\right)=C\left(y^{R}, r\right) \text { and } \frac{\partial C}{\partial y}\left(y^{R}, r\right)=0 .
$$

The situation $r=0$ corresponds to a no-regulation situation with $C(y, 0)=$ $c(y) / y$ so that $y^{R}(0)=y_{0}$ and $P\left(F^{R}(0)\right)=c\left(y_{0}\right) / y_{0}$. The quantity of food produced and the yield can be either increasing or decreasing with respect to the regulatory variable. Before considering some particular regulations, we can first provide an analysis without further specifying the regulation. This degree of generality allows to show the underlying mechanisms at stake.

Any change of the regulation has the following effect on welfare, given by equation (4):

$$
\begin{aligned}
\frac{d W}{d r} & =\frac{\partial W}{\partial F} F^{R \prime}+\frac{\partial W}{\partial y} y^{R \prime} \\
& =\left[P(F)-\frac{c(y)}{y}-\beta \frac{b(0)-b(y)}{y}\right] F^{R \prime} \\
& +\frac{F}{y^{2}}\left[c(y)-c^{\prime}(y) y+\beta\left(b^{\prime}(y) y+b(0)-b(y)\right)\right] y^{R \prime}
\end{aligned}
$$

At $r=0$, the price is equal to the $\operatorname{cost} c(y) / y$, and the yield is $y_{0}$ so that the derivative of welfare is:

$$
\frac{d W}{d r}=-\beta \frac{b(0)-b(y)}{y} F^{R \prime}+\left[\beta\left(b^{\prime}(y) y+b(0)-b(y)\right)\right] \frac{F}{y^{2}} y^{R \prime} .
$$

Whether a small increase of $r$ will be beneficial or not will depend of the sign of this expression. There is an unambiguous benefit from any reduction of the quantity of food produced (first term of 12). Indeed, whether an increase or a decrease of the yield is welfare enhancing depends of the densityyield curve. 
If the monotonicity of the yield and the food production are aligned with the welfare enhancing ones a small increase of the regulation will be beneficial. If this is not the case the comparison of the two terms will be needed and the demand elasticity will play a crucial role.

A general expression of a threshold elasticity is:

$$
\tilde{\epsilon}=\left(1+\frac{b^{\prime}\left(y_{0}\right) y_{0}}{b(0)-b\left(y_{0}\right)}\right) \frac{y^{R \prime}}{y_{0}} \frac{c\left(y_{0}\right) / y_{0}}{\partial C / \partial r}
$$

The first factor represents the gain from an increase of the yield relative to the gain from a reduction of the food consumption. The second factor is the rate of change of the yield with respect to the regulation, and the last factor the inverse of the rate of change of the marginal cost $C\left(y^{R}(r), r\right)$. In case of ambiguity about the merit of a small positive regulation, the demand elasticity should be compared with this ratio. The following Table summarizes the possible cases.

Proposition 3 The sign of the welfare effect of a small increase of the regulatory variable depends of the shape of the density-yield curve as follow:

\begin{tabular}{c|c|c|c|}
\multicolumn{2}{l|}{} & $\begin{array}{c}b \text { concave } \\
\left(y^{*}<y_{0}\right)\end{array}$ & $\begin{array}{l}b \text { convex } \\
\left(y^{*}>y_{0}\right)\end{array}$ \\
\hline \hline$F^{R \prime}<0$ & $y^{R \prime}<0$ & + & + if $\epsilon \leq \tilde{\epsilon},-$ otherwise \\
\hline$F^{R \prime}<0$ & $y^{R \prime}>0$ & + if $\epsilon \leq \tilde{\epsilon},-$ otherwise & + \\
\hline$F^{R^{\prime}}>0$ & $y^{R^{\prime}}>0$ & - & + if $\epsilon \geq \tilde{\epsilon},-$ otherwise \\
\hline$F^{R^{\prime}}>0$ & $y^{R \prime}<0$ & + if $\epsilon \geq \tilde{\epsilon}$, otherwise & - \\
\hline
\end{tabular}

\section{Proof.}

The price of food is equal to the marginal cost. Taking the derivative of the first equation in 10 gives (by the envelop theorem) $P^{\prime} F^{R \prime}=\partial C / \partial r$, so

$$
F^{R \prime}=\epsilon F \frac{\partial C / \partial r}{C(y, r)}
$$


Then, injecting the above equation into equation (15), the derivative of welfare is

$$
\begin{aligned}
\frac{d W}{d r} & =\beta \frac{F}{y}(b(0)-b(y))\left[-\epsilon \frac{\partial C / \partial r}{C(y, r)}+\left(1+\frac{b^{\prime}(y) y}{b(0)-b(y)}\right) \frac{y^{R \prime}}{y}\right] \\
& =\beta \frac{F}{y}(b(0)-b(y)) \frac{\partial C / \partial r}{C(y, r)}(\tilde{\epsilon}-\epsilon) \quad \text { using (13). }
\end{aligned}
$$

Let us consider that $\partial C / \partial r$ is positive, so $F^{R \prime}$ is negative.

- If $b($.$) is concave: The effect of the yield b(0)-b(y)+b^{\prime}(y) y$ is negative. If $y^{R \prime}$ is negative, then the two terms in the expression 15 of the derivative of welfare are positive and a small increase of $r$ has a positive effect.

If $y^{R \prime}$ is positive, the threshold $\tilde{\epsilon}$ is negative and from $(14)$, the derivative of welfare is positive if $\epsilon<\tilde{\epsilon}$ and negative otherwise.

- If $b($.$) is convex: The effect of the yield b(0)-b(y)+b^{\prime}(y) y$ is positive. And a simialr reasoning gives the results for the second row of the Table.

If $\partial C / \partial r$ is negative $F^{R \prime}$ is positive, a symmetrical reasoning could be applied to obtain the last two lines of the table.

Another way to look at the trade-off would be to write the derivative of welfare at $r=0$ grouping terms so that the effect of the regulation on farmland appears. Noting that $L^{\prime}=\left(F^{\prime} y-y^{\prime} F\right) / y^{2}$, from equation 12 , we get

$$
\frac{d W}{d r}=\beta b^{\prime}\left(y_{0}\right) L y^{R \prime}-\beta\left(\frac{b(0)-b(y)}{y}\right) L^{\prime}
$$

This expression emphasized the trade-off between yield and farmed area but it masked the role played by the demand price-elasticity. This expression still allows to get the following intuitive and reassuring result.

Corollary 1 A sufficient condition for a small regulation to improve welfare is that both the yield and the farmed area decrease.

Armed with these results we can now consider several particular regulations. 


\subsection{Subsidizing wildlife friendly farming}

We begin by considering the consequences of a subsidy that would only hold over farmed land. Let us denote by $s$ a subsidy on species specimen over farmland. This subsidy is constrained to be positive, that is a tax on specimen is not feasible. The profit of the representative land-owner is:

$$
\pi=P F-c(y) L+s b(y) L=P F-c(y) F / y+s b(y) F / y
$$

When choosing the yield over farmland the land-owner does not consider the effect of land-substitution between farmed and unfarmed land. He sets $y(s)$ and produces $F(s)$ so that

$$
P(F)=[c(y)-s b(y)] / y \text { and } c(y)-c^{\prime}(y) y=s\left[b(y)-b^{\prime}(y) y\right]
$$

When the subsidy increases, the farmer reduces the yield and increases its production of food. The consequence is indeed an increase of the total farmed area. Land-sparing is therefore not an option, and

Corollary 2 With a subsidy per specimen on farmland (and not on unfarmed area),

- If the density-yield curve is convex, the optimal subsidy is null.

- If the density-yield curve is concave, the optimal subsidy is null if $\epsilon<\tilde{\epsilon}$ and positive otherwise. The expression of the threshold is:

$$
\tilde{\epsilon}=\left(1+\frac{b^{\prime}\left(y_{0}\right) y_{0}}{b(0)-b\left(y_{0}\right)}\right)\left(1-\frac{b^{\prime}\left(y_{0}\right) y_{0}}{b\left(y_{0}\right)}\right) \frac{c\left(y_{0}\right)}{y_{0}^{2} c^{\prime \prime}}(<0)
$$

Proof. From the two equations (17), $F^{R}$ is increasing and $y^{R}$ is decreasing with respect to $s$. The situation corresponds to the third line of the table in proposition 3 .

The expression of the threshold is obtained by injecting into the general expression (13) the relation: $\partial C / \partial s=-b(y) / y$ and the derivative of the yield at $s=0$ (obtained from eq. (17)):

$$
y^{R \prime}(0)=\frac{b-b^{\prime}\left(y_{0}\right) y_{0}}{-c^{\prime \prime} y_{0}}
$$


To subsidize biodiversity over farmland has the adverse consequences of increasing the incentive to farm. If the species under consideration is very sensitive to the first increase of the yield ( $b$ convex) it is then clearly detrimental to subsidize in-farm biodiversity. The gains in the farm cannot compensate the loss due to increased farmland. However, if the species is resistant to the implementation of farming ( $b$ concave), the gains from the reduction of the yield in farms are not fully compensated by farms expansion if the demand for food is sufficiently inelastic. In that case, the food consumed does not increased much following the reduction of food price.

\subsection{Implementation of natural reserves}

Let us now consider the implementation of a natural reserve. This regulation would consist in setting $L=F / y$ the total farmed area. Equivalently, to better suit our general approach, the regulator can tax farmland, the regulatory variable is then the tax $t$. The profit of the representative land-owner is then

$$
\pi=P F-(c(y)+t) L=\left[P-\frac{c(y)+t}{y}\right] F
$$

The quantity of food produced decreases and the yield increases with respect to the tax. Indeed, the increase of the yield does not fully compensate the reduction of farmland.

Corollary 3 When the regulator envisions taxing or subsidizing farmland,

- If the density-yield curve is convex, farming should be taxed.

- If the density-yield curve is concave, farming should be taxed if $\epsilon<\tilde{\epsilon}$ and subsidized otherwise. The expression of the threshold is:

$$
\tilde{\epsilon}=\left(1+\frac{b^{\prime}\left(y_{0}\right) y_{0}}{b(0)-b\left(y_{0}\right)}\right) \frac{c\left(y_{0}\right)}{y^{2} c^{\prime \prime}}
$$

\section{Proof.}

With a tax on farmland, the marginal production cost of food is : $C(y, t)=$ $(c(y)+t) / y$, the two quantities $y^{R}(t)$ and $F^{R}(t)$ satisfy:

$$
c^{\prime}\left(y^{R}\right) y^{R}-c\left(y^{R}\right)=t \text { and } P\left(F^{R}\right)=\left(c\left(y^{R}\right)+t\right) / y^{R} .
$$


The quantity of food is decreasing and the yield is increasing with the regulatory variable and this case corresponds to the second line of the table in Proposition 3.

The particular expression of the threshold is obtained from equation (13) and the two following derivatives, at $t=0$ :

$$
\partial C / \partial t=1 / y_{0} \text { and } y^{R \prime}=1 / c^{\prime \prime}
$$

If the density-yield curve is convex, taxing farmland, or implementing natural reserve, is unambiguously good because it both reduces food consumption and increase the yield. Land is effectively spared and the species gains from this more than it looses from the increased yield in farms.

If the density yield curve is concave, in a first-best setting it would be optimal to reduce the yield which suggests that farmland should be subsidized. With an inelastic demand function farming should indeed be subsidized. However, if the demand function is sufficiently elastic, farming should be taxed because the loss of biodiversity within farms is compensates by the overall reduction of food consumption. The expression of the threshold elasticity is a product of two factors, the first being the negative relative loss of biodiversity from the increased yield, the second is the convexity of the cost function, which determines the sensitivity of the yield to an increase of the tax.

\section{4 taxing a dirty inputs}

A last possibility considered would be to tax the input responsible for the loss of biodiversity. Here, we will not consider substitution among inputs and only that the yield is determined by a quantity $q$ of pollutant inputs. The function $q(y)$ is the quantity of inputs required to get a yield $y$, it is null at zero, positive, increasing and convex. The function $b(y)$ is then an observed indirect relationship between the yield and the density that occurs via the quantity $q$.

If the regulator envisions taxing the input, the regulatory variable $r$ is the tax, and the profit of farmers:

$$
\pi=\left[P-\frac{c(y)+r q(y)}{y}\right] F
$$


The yield decreases with the tax on the input, and the food produced is reduced. Farmed area unambiguously decreases with the input tax.

Corollary 4 If the regulator can only tax or subsidize a pollutant input,

- If the density-yield curve is concave, the dirty input should be taxed,

- If the density-yield curve is convex, the dirty input should be taxed if $\epsilon<\tilde{\epsilon}$ and subsidized otherwise.

The expression of the threshold elasticity is

$$
\tilde{\epsilon}=\left(1+\frac{b^{\prime}\left(y_{0}\right) y_{0}}{b(0)-b\left(y_{0}\right)}\right)\left(1-\frac{q^{\prime}\left(y_{0}\right) y_{0}}{q\left(y_{0}\right)}\right) \frac{c\left(y_{0}\right)}{y_{0}^{2} c^{\prime \prime}}
$$

Proof. The two first order conditions are:

$$
c\left(y^{R}\right)+r q\left(y^{R}\right)-\left(c^{\prime}+r q^{\prime}\right) y^{R}=0 \text { and } P\left(F^{R}\right)=(c+r q) / y^{R}
$$

The derivative of the yield with respect to $r$ at $r=0$ is: $y^{R \prime}=\frac{1}{y_{0}} \frac{q-q^{\prime} y_{0}}{c^{\prime \prime}}$ which is negative. The derivative of the cost is $\partial C / \partial r=q\left(y_{0}\right) / y_{0}$. Therefore, the situation corresponds to the first (resp. third) line of the table in Proposition 3 for a tax (resp. a subsidy). Injecting these two derivatives into the general expression of the thresholds (13), gives the particular threshold (22).

If the density yield curve is concave, both the reduction of the food consumed and the reduction of the yield go in the right direction, from a welfare perspective.

If the density yield curve is convex, it would be optimal in a first-best setting to increase the yield and reduce the area farmed. However, if the demand for food is sufficiently elastic it is optimal in a second-best setting to tax the dirty input. Such a tax induces a reduction of the food consumed that ensures that the area farmed does not increase too much, if not decrease.

\section{Discussions}

Several important features that were not introduced in the model are likely to modify the results or their policy interpretation. Indeed, this theoretical analysis does not aim at providing definite answer about the optimal policy to 
protect a species, but mainly to consider how the optimal farming technique and conservation policy depend upon the type of policy used. Three issues are briefly discussed: the role of input substitution, technical progress and irreversibility.

The density-yield curve observed is the result of a complex interaction between farming practices and eco-system. Various farming practices can induce similar yields at different environmental cost. Indeed, organic farming can have high yield but it might require more work and knowledge than intensive farming. From a micro-economic perspective it would mean that it is possible to substitute dirty inputs (e.g. pesticides and fertilizer) with clean ones (e.g. labour and knowledge). And the meaningful economic evaluation of a technique is to determine the productivity of the various inputs.

The model should then be extended by writing the yield and the density of the species as functions of a vector of input quantities. The optimal inputs combination would depends on the value of the species. The environmental effect of an input would be its direct effect on in-farm density plus its indirect effect via land-use. The latter being related to the productivity of the input, it would likely exhibit decreasing return to scale. Clean inputs have a clear environmental benefits since they increase yield while preserving in-farm biodiversity. Whether dirty inputs should be more intensively used would depend on whether their influence on the yield is sufficient to compensate their in-farm environmental cost.

Substitution can also be difficult to handle and give rise to surprising consequences. For instance, if increasing the quantity of clean inputs increases the productivity of dirty ones it can reinforce the case for their use. The analysis of policy would be interestingly affected by such substitution patterns, since policies usually target some inputs and not others.

It is often argued that technical progress is a necessary ingredient to decouple economic growth from its environmental footprints, and, in particular, increase food production while reducing the environmental externalities of farming. An interesting question, related to the issue of input substitution, is the direction of technical change and the orientation of agronomic research toward the productivity of certain inputs.

Finally, the ecological dynamic of the model should be developed. The long history of farming in Europe is partly responsible to the current environmental situation, and the currently observed density-yield curve is actually the result of past choices. It would be nice to get dynamic trajectories of farming practices associated to the evolution of the species density. It would 
also help understand the impact of the irreversibility of some habitats destruction on the trade-off between land-sparing and land-sharing. Whether the quasi-option value associated to such irreversibility (Henry; 1974, Arrow and Fisher, 1974) reinforce or reduce the case for land-sparing is an important research question.

\section{Conclusion}

This article have analyzed the difficult tension between food production and nature conservation. The growth of human population rises a concern over a double difficulty ensuring food security and protecting eco-system. It seems that highly productive techniques (e.g. intensive farming) can ensure the former but sacrifice the latter. It is not necessarily so if these techniques allows to spare land for nature.

It has been shown that the optimal yield can be increasing with respect to the value of the threatened species. If this species is highly sensitive to the first increase of the yield, it is optimal in order to protect it to increase yield and spare land. However, wildlife-friendly farming even if at low-yield is not necessarily associated with an expanded farmland if the demand for food is sufficiently elastic.

Second best policies that cannot directly act upon both the yield and the farmed area will be welfare enhancing in certain conditions on the densityyield curve and the demand elasticity. For instance, if the density of the species is decreasing with respect to a dirty input it is optimal to tax this input and reduce the yield even in cases in which it would be optimal in a first-best setting to increase yield. This is so because the decrease of the yield is compensated by a decrease of the food consumed that ensures that farmed area does not much increase. However, if the demand function is inelastic then it can be optimal to subsidize a dirty input in order to spare land.

The analysis of the second-best setting, even if highly stylized, shows that policy recommendation a priori true in first-best setting are not necessarily true in second-best ones. One inspired by conservation purposes should not jump to the conclusion that a certain type of agriculture should be promoted because this type of agriculture is part of a first-best strategy. If the regulation is incomplete it could be welfare enhancing to promote a priori bad agricultural practices. 


\section{References}

Angelsen, A. and Kaimowitz, D. (1999). Rethinking the causes of deforestation: lessons from economic models, The world bank research observer 14(1): 73-98.

Arrow, K. and Fisher, A. (1974). Environmental Preservation, Uncertainty, and Irreversibility, The Quarterly Journal of Economics 88(2): 312-319.

Bamière, L., David, M. and Vermont, B. (2013). Agri-environmental policies for biodiversity when the spatial pattern of the reserve matters, Ecological Economics 85: 97-104.

Bengtsson, J., Ahnström, J. and Weibull, A.-C. (2005). The effects of organic agriculture on biodiversity and abundance: a meta-analysis, Journal of applied ecology 42(2): 261-269.

Chamberlain, D. E., Joys, A., Johnson, P. J., Norton, L., Feber, R. E. and Fuller, R. J. (2010). Does organic farming benefit farmland birds in winter?, Biology Letters 6(1): 82-84.

Christiaans, T., Eichner, T. and Pethig, R. (2007). Optimal pest control in agriculture, Journal of Economic Dynamics and Control 31(12): 39653985 .

Couvet, D., Desquilbet, M. and Dorin, B. (2013). Land sharing vs. land sparing for biodiversity: How agricultural markets make the difference, Toulouse School of Economics (TSE) working paper.

de Ponti, T., Rijk, B. and van Ittersum, M. K. (2012). The crop yield gap between organic and conventional agriculture, Agricultural Systems 108(0): $1-9$.

Eichner, T. and Pethig, R. (2006). Economic land use, ecosystem services and microfounded species dynamics, Journal of environmental economics and management 52(3): 707-720.

Ewers, R. M., Scharlemann, J. P., Balmford, A. and Green, R. E. (2009). Do increases in agricultural yield spare land for nature?, Global Change Biology 15(7): 1716-1726. 
Firbank, L. G., Petit, S., Smart, S., Blain, A. and Fuller, R. J. (2008). Assessing the impacts of agricultural intensification on biodiversity: a british perspective, Philosophical Transactions of the Royal Society B: Biological Sciences 363(1492): 777-787.

Fuller, R., Norton, L., Feber, R., Johnson, P., Chamberlain, D., Joys, A., Mathews, F., Stuart, R., Townsend, M., Manley, W., Wolfe, M., Macdonald, D. and Firbank, L. (2005). Benefits of organic farming to biodiversity vary among taxa, Biology Letters 1(4): 431-434.

Godfray, H. C. J. (2011). Food and biodiversity, Science 333(6047): 12311232.

Green, R. E., Cornell, S. J., Scharlemann, J. P. and Balmford, A. (2005). Farming and the fate of wild nature, Science 307(5709): 550-555.

Griffin, R. C. and Bromley, D. W. (1982). Agricultural runoff as a nonpoint externality: a theoretical development, American Journal of Agricultural Economics pp. 547-552.

Henry, C. (1974). Investment decisions under uncertainty: The "irreversibility effect", The American Economic Review 64(6): 1006-1012.

Lewis, D. J. and Plantinga, A. J. (2007). Policies for habitat fragmentation: combining econometrics with gis-based landscape simulations, Land Economics 83(2): 109-127.

Lewis, D. J., Plantinga, A. J. and Wu, J. (2009). Targeting incentives to reduce habitat fragmentation, American Journal of Agricultural Economics 91(4): 1080-1096.

Martinet, V. and Barraquand, F. (2012). Trade-offs between food production and biodiversity conservation: some economic aspects.

Parkhurst, G. M. and Shogren, J. F. (2007). Spatial incentives to coordinate contiguous habitat, Ecological Economics 64(2): 344 - 355. Special Section - Ecosystem Services and Agriculture Ecosystem Services and Agriculture.

Parkhurst, G. M., Shogren, J. F., Bastian, C., Kivi, P., Donner, J. and Smith, R. B. (2002). Agglomeration bonus: an incentive mechanism to reunite fragmented habitat for biodiversity conservation, Ecological Economics 41(2): $305-328$. 
Pethig, R. (2004). Agriculture, pesticides and the ecosystem, Agricultural Economics 31(1): 17-32.

Phalan, B., Onial, M., Balmford, A. and Green, R. E. (2011). Reconciling food production and biodiversity conservation: land sharing and land sparing compared, Science 333(6047): 1289-1291.

Rudel, T. K., Schneider, L., Uriarte, M., Turner, B. L., DeFries, R., Lawrence, D., Geoghegan, J., Hecht, S., Ickowitz, A., Lambin, E. F., Birkenholtz, T., Baptista, S. and Grau, R. (2009). Agricultural intensification and changes in cultivated areas, 1970-2005, Proceedings of the National Academy of Sciences 106(49): 20675-20680.

Seufert, V., Ramankutty, N. and Foley, J. A. (2012). Comparing the yields of organic and conventional agriculture, Nature 485(7397): 229-232.

Shortle, J. S., Abler, D. G. and Horan, R. D. (1998). Research issues in nonpoint pollution control, Environmental and Resource Economics 11(34): $571-585$.

Tschirhart, J. (2000). General equilibrium of an ecosystem, Journal of Theoretical Biology 203(1): 13-32. 